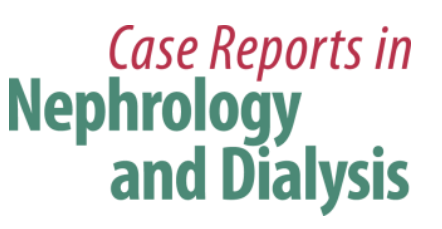

Case Rep Nephrol Dial 2019;9:119-125

DOI: 10.1159/000502436

Published online: August 28, 2019

(c) 2019 The Author(s)

Published by S. Karger AG, Basel

www.karger.com/cnd

This article is licensed under the Creative Commons Attribution-NonCommercial 4.0 International License (CC BY-NC) (http://www.karger.com/Services/OpenAccessLicense). Usage and distribution for commercial purposes requires written permission.

\title{
Gastrointestinal Manifestations in a Patient with Calciphylaxis: A Case Report
}

\author{
Shaun Jia Wei Kang ${ }^{a} \quad K^{2}$ rishan Madhan ${ }^{b}$ \\ aDepartment of Internal Medicine, Gold Coast Hospital and Health Service, \\ Southport, QLD, Australia; ${ }^{b}$ Department of Renal Medicine, Wide Bay Hospital and \\ Health Service, Bundaberg, QLD, Australia
}

\section{Keywords}

Calciphylaxis · End-stage kidney disease - Rectal necrosis · Gastrointestinal bleeding

\begin{abstract}
Calciphylaxis is a rare condition usually seen in patients with significant renal disease, affecting $1-4 \%$ of patients undergoing haemodialysis. Although the disease usually manifests as lesions in the subcutaneous tissue, there have been rare occurrences of calciphylaxis presenting as lesions in the gastrointestinal tract, leading to complications of bowel necrosis and haemorrhage. In view of this, we report the case of suspected gastrointestinal tract calciphylaxis in a 63-year-old patient with end-stage kidney disease (ESKD) who presented with painful swelling in the medial and lateral aspect of both thighs. Physical examination revealed extensive tender subcutaneous tissue nodules suggestive of calciphylaxis. During her hospital admission, the patient developed an episode of gastrointestinal bleeding requiring multiple blood transfusions. A computed tomography scan of the abdomen showed widespread vascular calcification within the aorta and its somatic and visceral branches as well as a splenic infarct. Oesophagogastroduodenoscopy revealed a large gastric ulcer, while flexible sigmoidoscopy revealed necrosis of the rectal mucosa. She was started on vitamin $D$ supplementation and intravenous sodium thiosulphate during each dialysis session. She clinically improved with no further gastrointestinal haemorrhage and partial resolution of her rectal necrosis and was transferred to a rehabilitation facility for further care and discharge planning.
\end{abstract}




\section{Case Reports in Nephrology and Dialysis}

\section{Introduction}

Calciphylaxis is a rare thrombotic vasculopathic disease which causes calcification in the microvasculature of adipose and subcutaneous tissues, leading to characteristic purpuric skin lesions in areas such as the abdominal wall and lower limbs [1, 2]. These lesions usually undergo necrosis due to poor small vessel circulation and form non-healing ulcers which are susceptible to infection [3]. Calciphylaxis is usually seen in patients with significant renal disease, affecting $1-4 \%$ of patients undergoing haemodialysis [3].

Although primarily a disease of the skin, there have been reports of calciphylaxis presenting as lesions in the gastrointestinal tract, leading to complications of bowel necrosis and haemorrhage [4,5]. In view of this, we report a case of suspected gastrointestinal tract calciphylaxis in a 63-year-old patient with end-stage kidney disease (ESKD), which manifested as gastrointestinal bleeding, ulceration of the gastric wall, and necrosis of the rectal wall on endoscopic examination.

\section{Case Report}

We report the case of a 63-year-old lady with a background of type 2 diabetes mellitus, hypertension, atrial fibrillation, and ESKD secondary to diabetic nephropathy. She had been dialysis dependent for 3 years. Some months before presentation, she had been started on warfarin for a $\mathrm{CHA}_{2} \mathrm{DS}_{2}$-VASc score of 3 . She initially presented with a 2-week history of painful swelling in the medial and lateral aspect of both thighs. There was no history of trauma. Physical examination revealed extensive tender nodules in the subcutaneous tissue around the gluteal region and bilateral proximal lower limbs. There was no evidence of cutaneous cellulitis suggesting infection, peripheral vascular disease, or ulceration. On the lateral aspect of the right lower limb, there was skin discolouration and mottling suggestive of impending skin breakdown.

Laboratory parameters at the time showed an elevated parathyroid hormone level of $104 \mathrm{pmol} / \mathrm{L}$, calcium $2.04 \mathrm{mmol} / \mathrm{L}$, and phosphate $1.17 \mathrm{mmol} / \mathrm{L}$. Her white cell count was normal and the C-reactive protein level was $20 \mathrm{mg} / \mathrm{L}$. The clinical picture was highly suggestive of extensive calciphylaxis, given the clinical setting of ESKD, recent commencement of vitamin $\mathrm{K}$ antagonists, and hyperparathyroidism. A radionuclide bone scan utilising technetium was performed and showed moderate tracer uptake in the adipose tissue of both medial and lateral thighs (Fig. 1).

The patient was started on intravenous sodium thiosulphate $25 \mathrm{~g}$ three times weekly during each session of haemodialysis. Warfarin was discontinued and arrangements were made for urgent parathyroidectomy. Postoperatively, hospital admission was complicated by multiple issues, including intermittent confusion. A magnetic resonance imaging scan of the brain showed chronic small vessel ischaemic changes. A splenic infarct was diagnosed incidentally on a computed tomography scan of the abdomen for investigation of abdominal pain, which also demonstrated widespread vascular calcification within the aorta and its somatic and visceral branches (Fig. 2). A transthoracic and transoesophageal echocardiogram excluded a mural thrombus which could have contributed to the splenic infarct. She then developed an episode of melaena requiring multiple blood transfusions. A large serpiginous gastric ulcer was found on oesophagogastroduodenoscopy (Fig. 3a). Helicobacter pylori testing was negative.

Two weeks following parathyroidectomy, the patient complained of pain around her anal region which worsened with defecation. Inspection revealed a protruding mass from the anus, 


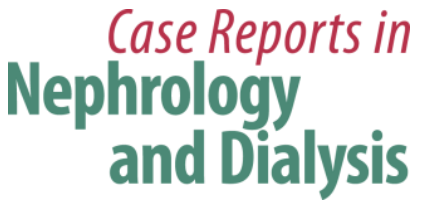

Case Rep Nephrol Dial 2019;9:119-125

DOI: $10.1159 / 000502436$

(c) 2019 The Author(s). Published by S. Karger AG, Basel www.karger.com/cnd

Kang and Madhan: Gastrointestinal Manifestations in a Patient with Calciphylaxis: A Case Report

which was malodorous and appeared necrotic. An urgent flexible sigmoidoscopy showed $10 \mathrm{~cm}$ of patchy ischaemic-looking rectal mucosa with near circumferential involvement around the anorectal junction (Fig. 3b, c), and necrotic mucosa prolapsing from anterior rectum. A rectal biopsy revealed necrotic tissue with patchy calcification in the sample, suggesting necrotic injury (Fig. 3d). There were unfortunately no viable blood vessels within the sample.

The patient was treated with broad-spectrum intravenous antibiotics and laxatives to ensure easy passage of faecal material. A proton pump inhibitor was administered to treat the gastric ulcer, with no further recurrence of gastrointestinal haemorrhage. Intravenous sodium thiosulphate was continued thrice weekly during her haemodialysis sessions. After discussion with the patient, we decided to commence her on aspirin and not on full anticoagulation due to her previous gastrointestinal bleed. Fortunately, her general condition improved, with resolution of some nodules and pain around the proximal lower limbs as well as resolution of pain in her anal and rectal regions. Repeated flexible sigmoidoscopy 1 month later revealed some slough in the rectal canal extending $4 \mathrm{~cm}$ from the anal verge with no active necrotic tissue. She was later transferred to a rehabilitation facility for ongoing rehabilitation and discharge planning.

\section{Discussion}

Calciphylaxis (also known as calcific uraemic arteriolopathy) is a rare thrombotic vasculopathic condition in which there is calcification of the microvasculature in adipose and subcutaneous tissue leading to intensely painful, purpuric skin lesions that often undergo necrosis and ulceration $[1,2]$. This in turn can lead to non-healing wounds that can result in sepsis and death [6]. Calciphylaxis carries a poor prognosis, and life expectancy is approximately less than 1 year once the disease is diagnosed [3]. This condition was first described in 1961 and is a rare complication in patients with ESKD, affecting around 1-4\% of patients on haemodialysis, but can also affect patients in earlier stages of renal impairment, kidney transplant recipients, and rarely patients with normal renal function $[2,7,8]$. Other risk factors for calciphylaxis include obesity, female sex, hyperparathyroidism, diabetes mellitus, and the use of vitamin $\mathrm{K}$ antagonists [2, 3].

The pathogenesis behind calciphylaxis is poorly understood. However, a two-stage process is thought to be the underlying mechanism. The first process involves vascular injury, characterised by calcification of microvessels, intimal hyperplasia, and endovascular fibrosis $[9,10]$. The second stage of the disease is usually initiated by some form of insult (i.e., trauma, hypotension, or thrombosis) leading to infarction, dystrophic calcification, or ulceration [8].

Clinical suspicion is crucial for early diagnosis. Skin biopsy is the standard method for diagnosing calciphylaxis, but this runs the risk of provoking new or exacerbating non-healing ulcers in patients [3]. Since our patient did not have any existing breaks in her skin, we elected not to perform a skin biopsy. However, a technetium radionuclide scan demonstrated extensive deposition of the isotope in the subcutaneous tissues that was highly suggestive of the disease. Histology usually shows calcification and necrosis in the microvessels in subcutaneous adipose tissue and dermis, often accompanied by necrosis, separation of the dermal and epidermal border, panniculitis, extravascular calcification, and proliferation of dermal endothelial cells $[6,10]$.

Calciphylaxis usually causes necrosis in areas where adipose tissue is abundant, and common areas include the abdominal wall, breasts, and thighs [7]. However, there have been case 


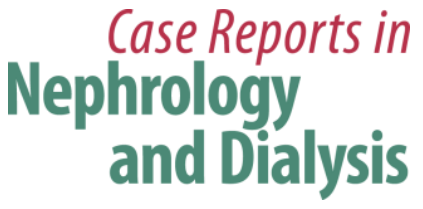

Case Rep Nephrol Dial 2019;9:119-125

DOI: $10.1159 / 000502436$

(c) 2019 The Author(s). Published by S. Karger AG, Basel www.karger.com/cnd

Kang and Madhan: Gastrointestinal Manifestations in a Patient with Calciphylaxis: A Case Report

reports of calciphylaxis affecting visceral organs and the gastrointestinal tract, leading to complications of gastrointestinal bleeding and bowel necrosis [4, 5]. A study by Coates et al. [11] in 1998 involving 16 patients with calciphylaxis described 2 patients suffering from gastrointestinal haemorrhage, and a separate case report by Gupta et al. [5] in 2015 showed evidence of severe rectal ulceration in a patient with calciphylaxis.

Although the exact aetiology of our patient's gastric ulcer and rectal ischaemia could not be confirmed, the clinical picture is highly suggestive of calcific uraemic arteriopathy of visceral blood vessels as a cause of the gastrointestinal manifestations. Her abdominal computed tomography, which demonstrated extensive calcification within the aorta and its tributaries, as well as the rectal sample, which showed extensive necrosis and calcification within the soft tissue, were in keeping with the extravascular manifestations of the disease [3]. The degree of ischaemia noted in the rectum was also deemed too severe to be caused by atherosclerosis alone. These findings led us to conclude that calciphylaxis had contributed to the development of the rectal ischaemia, the gastric ulcer, and the splenic infarct.

The treatment of calciphylaxis remains challenging as there is no globally accepted treatment modality for the condition, due in part to the rarity of the disease and the lack of large multicentre trials [3]. Methods that have been shown to be beneficial include adequate wound care, phosphate and calcium control, control of hyperparathyroidism, and hyperbaric oxygen therapy $[1,3,11]$. Intravenous sodium thiosulfate is a powerful antioxidant and chelating agent and is traditionally indicated for cyanide poisoning [9]. It has vasodilatory effects and inhibits adipocyte calcification, and is frequently used in treating calciphylaxis $[9,12]$. Use of intralesional sodium thiosulphate is also emerging as an adjunct to treatment for calciphylaxis, with Isoherranen et al. [13] describing complete to near-complete resolution of lesions in 3 out of 4 patients with injections done around the ulcer border.

For patients presenting with gastrointestinal necrosis or bleeding secondary to calciphylaxis, management would include resection of the affected segment of the gastrointestinal tract, provided that the patient's prognosis is favourable and that the area is amenable to resection [11]. In this patient, the area of rectal necrosis was resected, and the rest of her rectum and gastrointestinal tract was spared as there was viable tissue present.

\section{Conclusion}

Calciphylaxis is a thrombotic vasculopathic condition with high morbidity and mortality rates and significantly affects patients' quality of life and survival once diagnosed [1, 2]. Although rare, gastrointestinal manifestations of calciphylaxis should always be suspected in patients with suggestive skin lesions or in patients with renal disease so as to ensure that such patients can be investigated and managed promptly and effectively.

\section{Acknowledgement}

The authors acknowledge the contribution of Dr. Angela Ratsch, Director of Research Education, Development and Support, Wide Bay Hospital and Health Service to the preparation of the manuscript and the submission process. 


\section{Statement of Ethics}

The patient provided verbal and written consent to participate in this case report and for all information and images to be used in this paper. The case report was approved by the Wide Bay Hospital and Health Services.

\section{Disclosure Statement}

The authors have no conflicts of interest to declare.

\section{Author Contributions}

S.J.W. Kang contributed to the study design, literature search, and manuscript preparation of the project and participated in the management of the patient. K. Madhan contributed to the manuscript preparation and oversaw the clinical management of the patient. Both authors read and approved the final manuscript.

\section{References}

1 McCarthy JT, El-Azhary RA, Patzelt MT, Weaver AL, Albright RC, Bridges AD, et al. Survival, risk factors, and effect of treatment in 101 patients with calciphylaxis. Mayo Clin Proc. 2016 Oct;91(10):1384-94.

2 Nigwekar SU, Kroshinsky D, Nazarian RM, Goverman J, Malhotra R, Jackson VA, et al. Calciphylaxis: risk factors, diagnosis, and treatment. Am J Kidney Dis. 2015 Jul;66(1):133-46.

3 Nigwekar SU, Thadhani R, Brandenburg VM. Calciphylaxis. N Engl J Med. 2018 May;378(18):1704-14.

4 Tamura M, Hiroshige K, Osajima A, Soejima M, Takasugi M, Kuroiwa A. A dialysis patient with systemic calciphylaxis exhibiting rapidly progressive visceral ischemia and acral gangrene. Intern Med. 1995 Sep; 34(9):908-12.

5 Gupta N, Haq KF, Mahajan S, Nagpal P, Doshi B. Gastrointestinal bleeding secondary to calciphylaxis. Am J Case Rep. 2015 Nov; 16:818-22.

6 Weenig RH, Sewell LD, Davis MD, McCarthy JT, Pittelkow MR. Calciphylaxis: natural history, risk factor analysis, and outcome. J Am Acad Dermatol. 2007 Apr;56(4):569-79.

7 Hayashi M. Calciphylaxis: diagnosis and clinical features. Clin Exp Nephrol. 2013 Aug;17(4):498-503.

8 Wilmer WA, Magro CM. Calciphylaxis: emerging concepts in prevention, diagnosis, and treatment. Semin Dial. 2002 May-Jun;15(3):172-86.

9 Cohen GF, Vyas NS. Sodium thiosulfate in the treatment of calciphylaxis. J Clin Aesthet Dermatol. 2013 May; 6(5):41-4.

10 Chen TY, Lehman JS, Gibson LE, Lohse CM, El-Azhary RA. Histopathology of calciphylaxis: cohort study with clinical correlations. Am J Dermatopathol. 2017 Nov;39(11):795-802.

11 Coates T, Kirkland GS, Dymock RB, Murphy BF, Brealey JK, Mathew TH, et al. Cutaneous necrosis from calcific uremic arteriolopathy. Am J Kidney Dis. 1998 Sep;32(3):384-91.

12 Yu Z, Gu L, Pang H, Fang Y, Yan H, Fang W. Sodium thiosulfate: an emerging treatment for calciphylaxis in dialysis patients. Case Rep Nephrol Dial. 2015 Mar;5(1):77-82.

13 Isoherranen K, Bouchard L, Kluger N. Benefits of intralesional injections of sodium thiosulfate in the treatment of calciphylaxis. Int Wound J. 2017 Dec;14(6):955-9. 


\section{Case Reports in \\ Nephrology and Dialysis}

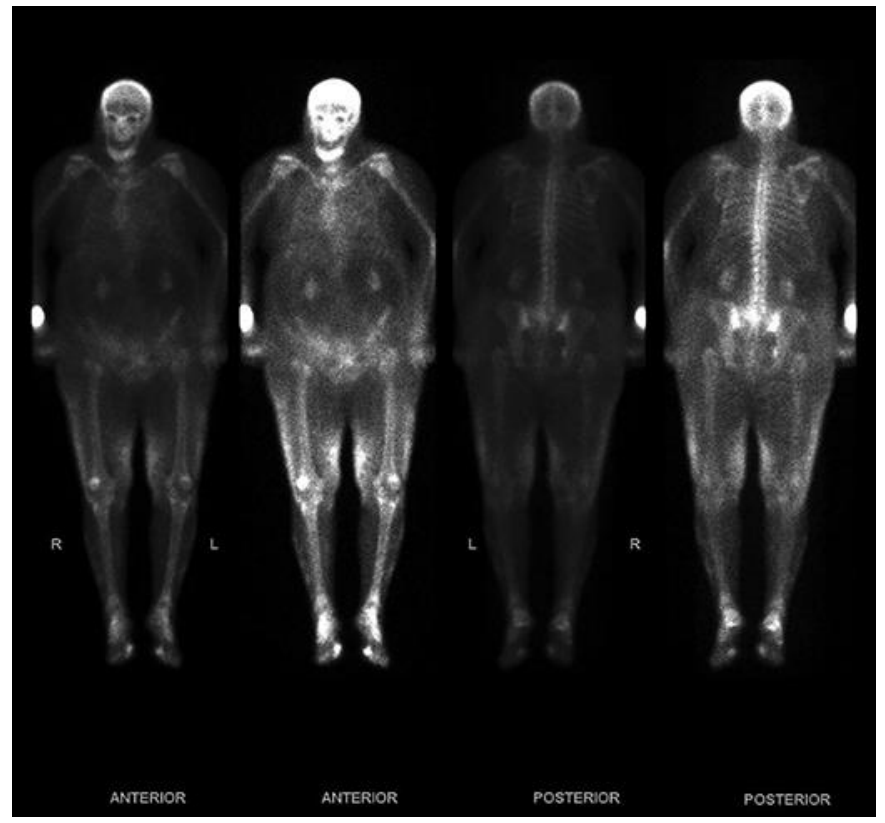

Fig. 1. Bone scan showing moderate tracer uptake in the adipose tissue of both the medial and lateral thighs.

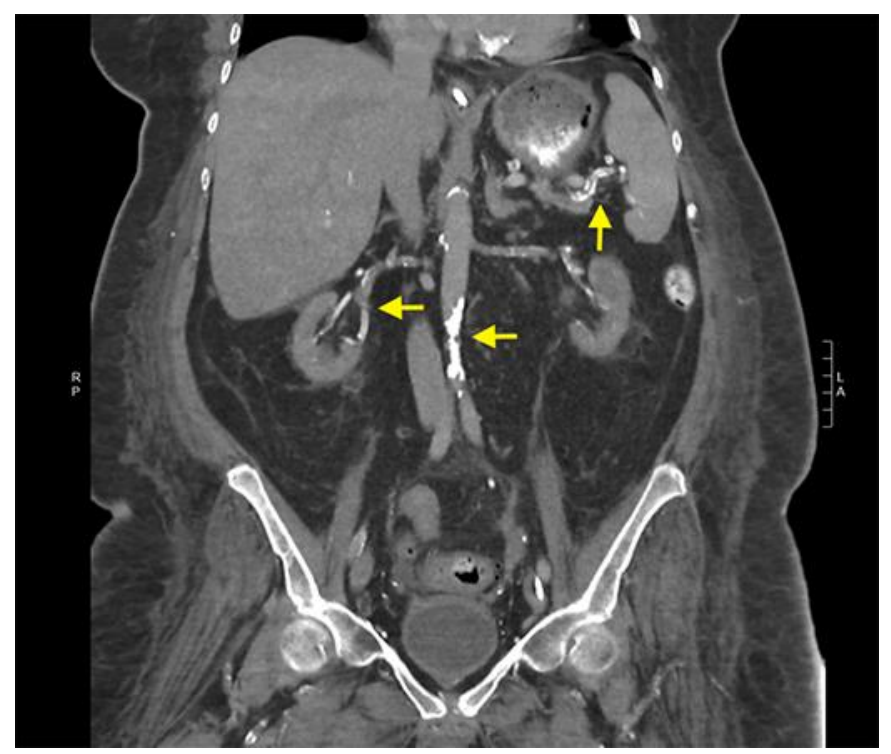

Fig. 2. Coronal view of a computed tomography scan of the abdomen showing widespread vascular calcification (areas of calcification indicated by yellow arrows). 


\section{Case Reports in Nephrology and Dialysis}

Case Rep Nephrol Dial 2019;9:119-125

DOI: $10.1159 / 000502436$

(c) 2019 The Author(s). Published by S. Karger AG, Basel www.karger.com/cnd

Kang and Madhan: Gastrointestinal Manifestations in a Patient with Calciphylaxis: A Case Report
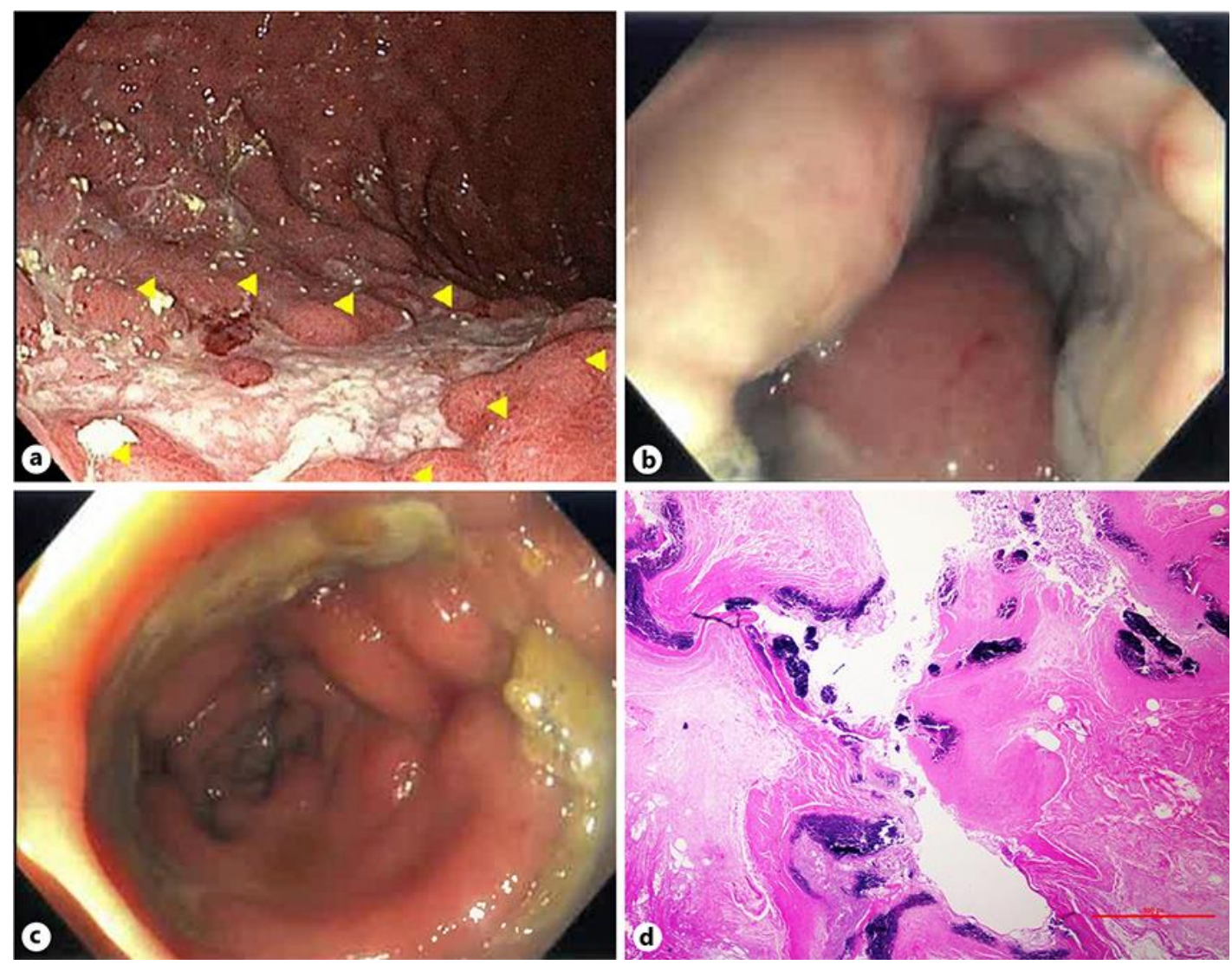

Fig. 3. a Gastric ulcer on the lesser curvature of the stomach (borders of ulcer indicated by yellow arrows). b, c Images taken during flexible sigmoidoscopy showing rectal mucosa ischaemia. $\mathbf{d}$ Microscopic appearance of rectal biopsy under haematoxylin and eosin stain showing necrotic tissue with patchy calcification. 